\title{
Entrevista
}

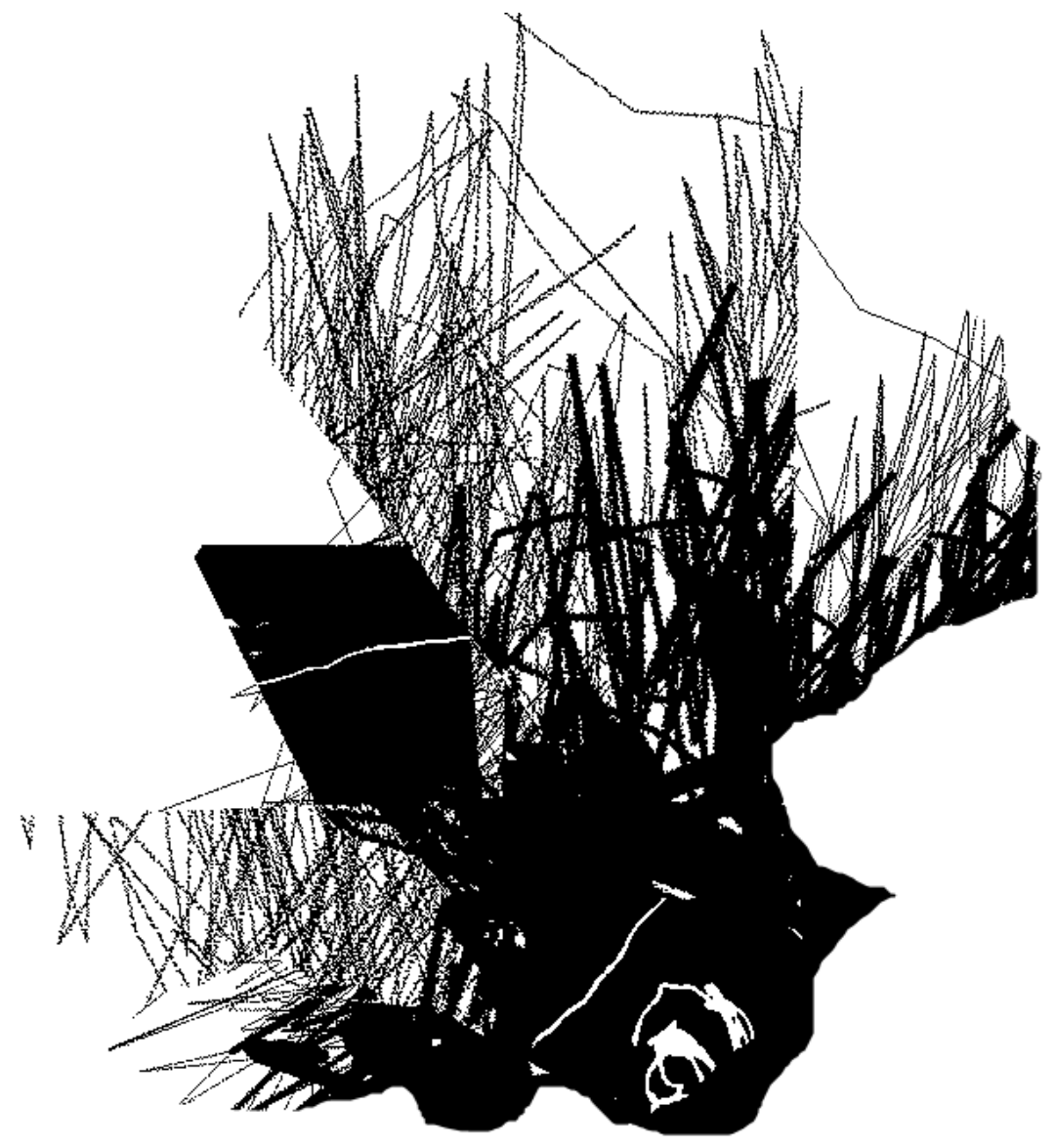





\section{Educação inclusiva e seus desafios: uma conversa com David Rodrigues}

Cássia Geciauskas Sofiatol

Carla Biancha Angeluccil

\section{Resumo}

A educação inclusiva, no âmbito da educação especial, tem sido constantemente debatida por pesquisadores de diversas partes do mundo. Em 2015, ocorreu na Universidade de Lisboa o $8^{\text {th }}$ Inclusive and Supportive Education Congress: equity and inclusion in education, reunindo congressistas de 38 países, entre eles professores, pesquisadores, líderes políticos e representantes de instituições. A coordenação geral ficou a cargo do Prof. Dr. David Rodrigues, entre outros profissionais, dado o reconhecimento de sua vasta contribuição no campo da educação especial, especificamente com o tema educação inclusiva. Esse foi o contexto gerador da proposta de entrevista. 0 percurso da entrevista é organizado a partir das experiências de David Rodrigues como estudante, professor e ativista envolvido profundamente com a garantia do direito à educação para todos. Sua densidade biográfica revela o caráter que a educação inclusiva assume em sua vida. Não se trata de um objeto de estudo, que deve ser escrutinado desde fora, sem envolvimento. Trata-se de uma causa: a educação como direito universal, realizado na convivência, reconhecendo e se constituindo a partir das diferenças humanas. Assim é que o Prof. David discorre sobre a necessidade do redimensionamento do trabalho pedagógico para a inclusão de todos os alunos e da importância da formação de professores nesse contexto. Para tanto, analisa conceitos como inclusão e equidade à luz da Declaração de Incheon, documento organizado pela Organização das Nações Unidas para a Educação, a Ciência e a Cultura, em 2015, durante o Fórum Mundial de Educação, na Coreia do Sul.

\section{Palavras-chave}

Educação especial - Educação inclusiva - Educação para todos.

I- Universidade de São Paulo, São

Paulo, SP, Brasil.

Contatos: cassiasofiato@usp.br;

b.angelucci@usp.br 


\title{
Inclusive education and its challenges: a conversation with David Rodrigues
}

\author{
Cássia Geciauskas Sofiato' \\ Carla Biancha Angeluccil
}

I- Faculdade de Educação. Universidade de São Paulo. São Paulo, SP, Brasil.

Contact: cassiasofiato@usp.br;

b.angelucci@usp.br.

\begin{abstract}
Inclusive education in the context of special education has been constantly debated by researchers from all over the world. In 2015, the 8th Inclusive and Supportive Education Congress: equity and inclusion in education was held at Universidade de Lisboa, bringing together delegates from 38 countries, including teachers, researchers, political leaders, and representatives of institutions. Professor David Rodrigues was one of the general coordinators of the congress, in recognition for his extensive contribution to the field of special education, and specifically to inclusive education. This was the context of the interview, which was organized taking into account the experience of Professor Rodrigues as a student, professor and activist deeply involved with the guarantee of the right to education for all. Its biographic content reveals the character that inclusive education takes in his life. Rather than an object of study - which should be scrutinized from outside, without engagement -, it is a cause: education as a universal right, performed living together, recognizing and constituting itself based on human differences. Thus Professor Rodrigues discusses the need for rethinking educational work to include all students and the importance of teacher education in this context. He analyzes concepts such as inclusion and equity in the light of the Declaration of Incheon, a document organized by The United Nations Educational, Scientific and Cultural Oragnization (UNESCO) in 2015, during the World Education Forum in South Korea.
\end{abstract}

\section{Keywords}

Special education - Inclusive education - Education for all. 


\section{Apresentação}

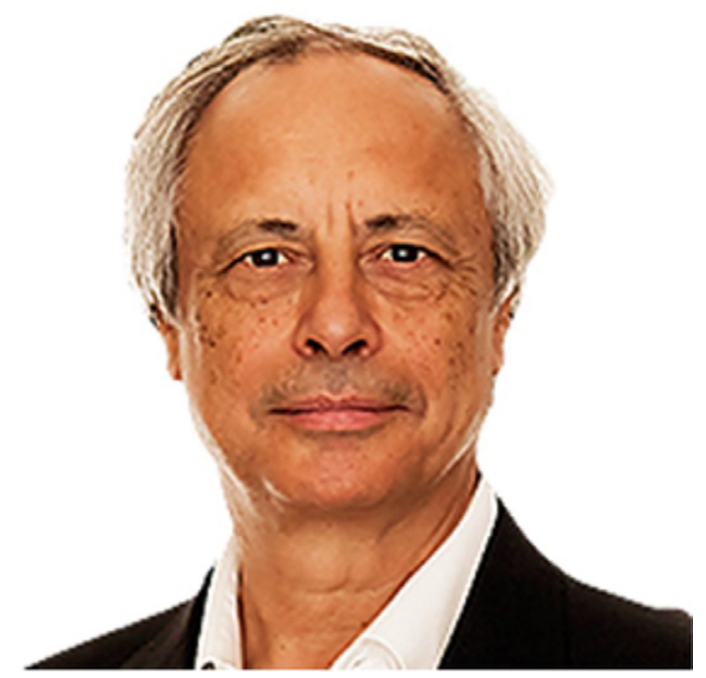

Fonte: arquivos pessoais do entrevistado.

Desde a tartaruga nada não era veloz. Depois é que veio o forde 22 E o asa-dura (máquina avoadora que imita os pássaros, e tem por alcunha avião)

Não atinei até agora porque é preciso andar tão depressa. Até há quem tenha cisma com a lesma porque ela anda muito depressa.

Eu tenho. A gente só chega ao fim quando o fim chega! Então pra que atropelar?

Manoel de Barros. A Tartaruga. 2013

Inclusão e equidade na e por meio da educação são o alicerce de uma agenda de educação transformadora e, assim, comprometemo-nos a enfrentar todas as formas de exclusão e marginalização, bem como disparidades e desigualdades no acesso, na participação e nos resultados de aprendizagem. Nenhuma meta de educação deverá ser considerada cumprida a menos que tenha sido atingida por todos.

0 conjunto da obra de David Rodrigues é denso, exigindo-nos tempo e exercício constante da radicalidade. Professor na Universidade Técnica de Lisboa desde 1980, autor de mais de trinta livros sobre educação inclusiva, David
Rodrigues já foi vice-presidente pela Europa da Sociedade Internacional para Estudos da Criança.

Em sua trajetória, não cabe distinguir ativismo, pesquisa e docência. Com o Prof. David Rodrigues, temos que a produção de conhecimento ocorre de maneira integral, a partir da imersão na realidade que, interpelando incessantemente os conhecimentos consolidados, convocando-nos a revisitar o sentido de e o compromisso com nossas escolhas. Provoca-nos a investigar o quanto temos sustentado afirmações tão simples quanto basilares como a determinação de educar todos os alunos e a educação sempre conviveu com a possibilidade de perder alguns alunos, para, em sequência, colocar em análise os aspectos socioculturais que constituem a vida diária escolar, a política educacional, a formação de professores.

$\mathrm{Na}$ entrevista, partimos do terreno da memória do estudante e do professor David para, então, solicitar reflexões a respeito de sua práxis. Ressaltamos a discussão sobre os desafios da educação inclusiva e o sentido ético-político da Declaração de Incheon (2015) desde seu ponto de vista.

David Rodrigues é formado em educação física, tendo produzido sobre psicomotricidade, atividades corporais e coordenado o curso de Terapias Expressivas (1999), na Faculdade de Motricidade Humana. Foi embaixador paralímpico em 1999, em Pequim. Recebeu o prêmio internacional de investigação União Latina, em 2007, e a medalha de mérito da Pró-Inclusão, em 2013.

Seu vínculo com a universidade se expressa, além das atividades docentes, pelos vários cargos ocupados e por sua contribuição como professor convidado em inúmeros países da Europa, das Américas e da África. Destacamos sua expressiva contribuição em países lusófonos, como Brasil e Cabo Verde, nos quais sua obra é difundida por meio de palestras e publicação de livros.

0 Prof. David Rodrigues ainda colabora significativamente em órgãos supranacionais como iniciativas da Unesco, da Unicef e da 
Handicap International, tendo representado Portugal em vários projetos europeus, tais como Helios II e Tempus (na Ucrânia, Lituânia e Rússia). Integrou ainda o grupo de peritos sobre inclusão social junto ao Conselho da Europa. Atualmente, é membro do Conselho Nacional de Educação, em Portugal. Participa ainda do Centro de Investigação em Educação do Instituto de Educação da Universidade de Lisboa, do Conselho Consultivo da Sociedade Portuguesa de Ciências da Educação e das equipes da Agência de Avaliação e Acreditação do Ensino Superior. É presidente da Associação Nacional de Docentes de Educação Especial.

Sua significativa contribuição para os estudos sobre educação inclusiva pode ser conhecida por meio de livros de sua autoria ou que contam com sua organização/ colaboração como autor de capítulos. Sua obra também pode ser conhecida por meio dos inúmeros artigos escritos para sites e para revistas de divulgação de debates sobre educação. Vem ainda compondo corpo editorial de revistas em Portugal, Brasil, Espanha, França e Reino Unido. É colunista regular de $O$ Público, A Página de Educação e Plural \&t Singular.

No Brasil, seu livro Inclusão e Educação: doze olhares sobre a educação inclusiva (2006) tem sido amplamente utilizado. Trata-se de coletânea em que vários autores colocam em análise a educação inclusiva, seja refletindo sobre o lugar que a discussão sobre a diferença tem ocupado no cenário educacional, seja debatendo a produção das políticas educacionais, a formação de professores, a participação social. Nesse contexto, o capítulo do Prof. David Rodrigues "Dez ideias (mal) feitas sobre educação inclusiva" parte de algumas afirmações repetidas à exaustão por educadores nos últimos quinze anos para, então, explicitar a permanência de concepções que sustentam a escola como instituição excludente e a educação como privilégio de alguns, e não como direito de todos.

A EI [educação inclusiva] tornou-se assim um campo polêmico por várias razões. Uma das principais é sem dúvida a contradição entre a letra da legislação e a prática das escolas. 0 discurso da inclusão ou "a ideologia da inclusão” (CORREIA, 2003) não tem frequentemente uma expressão empírica, e por vezes fala-se mais da EI como um mero programa político ou como uma quimera inatingivel do que como uma possibilidade concreta de opção numa escola regular. Tanto a legislação como o discurso dos professores se tornaram rapidamente "inclusivos", enquanto as práticas na escola só muito discretamente tendem a ser mais inclusivas. Recentemente, afırmamos que "é preciso não invocar o nome da inclusão em vão", tentando "mapear" esta distância entre os discursos e as práticas. (RODRIGUES, 2006, p. 302).

Já em livro organizado em 2011, Educação Inclusiva: dos conceitos às práticas de formação, David Rodrigues toma a questão das diferenças e do direito universal à educação para compartilhar olhares sobre aspectos da formação docente. É assim que podemos acompanhar discussões sobre aprendizagem cooperativa, experiências de inclusão, necessidades de reformulação da política de formação docente. A partir de pesquisa empírica realizada em Portugal, no capítulo "Formação de professores e inclusão: como se reformam os reformadores?”, Rodrigues e Lima-Rodrigues, apresentam as seguintes recomendações: atitude de investigação, práticas reflexivas, relação entre teoria e prática e contato com situações práticas.

A Educação necessita de uma reforma no sentido da Inclusão e, para isso, precisa de ter os seus próprios agentes, os seus próprios reformadores. Entretanto, em muitos sistemas educacionais - e, certamente, no sistema português - espera-se que os dinamizadores desta reforma a desenvolvam de uma forma, diríamos "metafísica”; isto é, que devem lutar por uma escola que, na verdade, nunca viram, que 
nunca experimentaram, e que sejam capazes de adotar métodos diferentes daqueles em que foram educados. É certo que os grandes promotores da Educação inclusiva da atualidade nunca experimentaram a Inclusão na sua vida escolar. Chegaram à premência da Educação Inclusiva através do seu próprio convencimento quanto à ética e à justiça da Inclusão. Não deixa de ser estimulante que impulso poderá sofrer a Educação Inclusiva quando esta deixar de ser desenvolvida por pessoas para quem ela não é mera opção ética, mas sim, o resultado de uma experiência pessoal e vivida (RODRIGUES; LIMARODRIGUES, 2016, p. 106).

Em 2016, é publicado Direitos humanos e inclusão, livro com um conjunto de textos do Prof. David Rodrigues, originados de suas palestras e demais atividades formativas. É a partir da discussão sobre a universalização da garantia de direitos, que o autor traz elementos para pensarmos as transformações possíveis e necessárias das várias dimensões da educação escolar, tais como a política, a arquitetura, a formação, o projeto da escola, a participação comunitária. 0 autor retoma, assim, o enfrentamento de uma antiga e emblemática questão: quais são as barreiras a serem superadas para que cada criança, para que toda criança possa permanecer na escola?

Com esta entrevista, procuramos conhecer, a partir da retomada de aspectos da trajetória de vida do Prof. Dr. David Rodrigues, experiências e valores fundantes para a defesa e a promoção do direito à educação inclusiva.

\section{Referências}

BARROS, Manuel de. A tartaruga. In: BARROS, Manuel de. Tratado geral das grandezas do ínfimo. São Paulo: LeYa, 2013. (Biblioteca Manoel de Barros).

PERRENOUD, Phillipe. Ensinar: agir na urgência, decidir na incerteza: saberes e competências em uma profissão complexa. Porto Alegre: Artmed, 2001.

RODRIGUES, David. Direitos humanos e inclusão. Porto: Profedições, 2016.

RODRIGUES, David. Inclusão e educação: doze olhares sobre a educação inclusiva. São Paulo: Summus, 2006.

RODRIGUES, David; LIMA-RODRIGUES, Luiza. Formação de professores e inclusão: como se reformam os reformadores? In: RODRIGUES, David. Educação inclusiva: dos conceitos às práticas de formação. Lisboa: Instituto Piaget, 2011. p. 89-108.

SANTOS, Boaventura Sousa. Educação. Jornal de Letras, Artes e Ideias, Lisboa, n. 1185, 02 a 15 mar. 2016.

UNESCO. Organização das Nações Unidas para a Educação, a Ciência e a Cultura. Declaração de Incheon educação 2030: rumo a uma educação de qualidade inclusiva e equitativa e à educação ao longo da vida para todos. Brasília, DF: Unesco, 2015. Disponivel em: <http://unesdoc.unesco.org/images/0023/002331/233137POR.pdf>. Acesso em: 19 ago. 2016. 


\section{A entrevista}

Inclusão e equidade na e por meio da educação são o alicerce de uma agenda de educação transformadora e, assim, comprometemo-nos a enfrentar todas as formas de exclusão e marginalização, bem como disparidades e desigualdades no acesso, na participação e nos resultados de aprendizagem. Nenhuma meta de educação deverá ser considerada cumprida a menos que tenha sido atingida por todos (UNESCO, 2015).

Como era a escola que David, criança e adolescente, viveu? Quais são as memórias que carrega da escola como estudante?

Falar da escola em que fui educado parece uma empresa arqueológica. Eu nasci perto da cidade do Porto, em Portugal, filho de uma família de classe média baixa. Quando fui para a escola já sabia ler, pois no andar térreo da casa em que eu morava funcionava uma escola e eu passava os meus dias lá para brincar com as crianças (mais velhas) que frequentavam a escola. Eu era uma espécie de "mascote" da escola... Quando dei por mim... sabia ler... teria, segundo os meus pais, quatro anos a chegar aos cinco. Lembro-me do prazer de aprender, de decifrar e de ser valorizado pelo que tinha aprendido. Aos seis anos entrei formalmente numa escola pública bem perto de casa e lá tudo me era familiar: o ser aluno, o ser professor, a forma de ensinar e de aprender, a organização do dia e dos períodos escolares. A minha escola era o arquétipo do que hoje se chama uma escola tradicional: transmissiva, repetitiva e frequentemente assustadora. As faltas de estudo ou de disciplina eram bem assinaladas com umas reguadas dadas com a "Santa Luzia", nome irônico dado à régua que tinha a função de nos iluminar o espírito... Lembro-me, claro, do tempo que tínhamos para brincar, para inventar jogos a partir de uma casca de laranja, de um risco no chão de uma cápsula de refrigerante, de uma bola feita com uma meia etc. etc. Uma coisa me intrigou: quando terminei o quarto ano e devia seguir para o nível de escolaridade seguinte, dos 29 alunos que éramos só eu fui para o liceu. Eu fiquei a pensar porque é que os meus colegas que tinham sido aprovados como eu não prosseguiram os estudos... E só mais tarde descobri a resposta. Esta resposta surgiu quando eu reparei que os meus colegas do liceu eram muito mais parecidos comigo em termos de capital cultural do que os meus antigos colegas. Percebi, então, que o mérito de ter chegado ao liceu se devia mais à minha filiação sociocultural do que a uma capacidade minha. Claro que isso hoje parece arqueológico... Hoje, em Portugal, a escolaridade é obrigatória até aos dezoito anos numa escola pública que funciona em tempo integral. Muito se caminhou... Portugal foi dos países da Organização para Cooperação e Desenvolvimento Econômico (OCDE) que mais progrediu em educação e ocupamos, nos estudos de avaliação transnacionais, posições onde se verificam os efeitos deste esforço educativo.

Mas regressando... o Liceu correspondia aos anos finais do ensino fundamental e essa escola que também tinha o ensino médio era austera e muito organizada. Lembro-me de ter sido feliz lá, talvez por duas razões: porque tinha uma vida rica fora da escola (música, teatro e atividade política), e porque a escola era bem previsivel e securizante. Sabíamos com uma margem mínima de erro o que se esperava de nós e o que era preciso fazer e, feito isto, o tempo era nosso.

Não posso falar de vivências inclusivas no meu percurso escolar: lembro-me vagamente de um colega com uma sequela de poliomielite que andava de muletas na minha escola fundamental e lembro-me de ele ser um excelente goleiro (defendia a bola também com as muletas). Mas a escola que frequentei tinha uma estrutura meritocrática em que se ensinava para o aluno bom ou médio e em que os alunos com dificuldades não tinham outro apoio que não fosse em casa ou nas "explicações" que os pais pudessem pagar. Eu tive também que ter "explicações" de matemática no sétimo ano de escolaridade e, assim, acabar com o mito de ser autossuficiente...

Fiz depois um curso de pedagogia (na área de educação física) e fui professor em vários graus de ensino. Especializei-me em educação 
especial e depois ingressei na universidade, onde fiz mestrado, doutorado e livre-docência. Um percurso que eu avalio como rico, exigente e feliz.

Como o senhor foi se aproximando da temática da educação inclusiva?

Um dia era eu professor numa escola de ensino fundamental e estava ao fim da tarde, depois de terminadas as aulas, a preparar algo para as aulas seguintes quando fui visitado por uma professora do Centro de Paralisia Cerebral em Lisboa que me vinha pôr uma questão muito simples: tinham-lhe dado boas referências do meu trabalho e ela vinha perguntar-me se eu queria ser professor de alunos com paralisia cerebral (na verdade, eu mal sabia o que era a paralisia cerebral). Pedi uma visita preliminar à minha resposta e... fui... e fiquei. Fiquei lá cinco anos. Este era ainda um tempo de "educação especial”, em que a "integração" dava os seus primeiros passos. Mas aqui aprendi a importância da equipe e da cooperação entre os docentes e técnicos. Aprendi que, se não existisse uma comunicação e uma aprendizagem conjunta sobre casos que eram inevitavelmente muito complexos, nós, os professores e técnicos, ficávamos com uma enorme sensação de impotência e de solidão. Nestes meus anos de trabalho, aprendi muito e sempre me ficou a certeza de que, se o professor não aprender e só ensinar, é um profissional incompleto e sujeito a um rápido esgotamento dos seus recursos (o que eu chamo o síndrome do "limão espremido").

Como professor do ensino fundamental tive uma experiência que muito me marcou e relatei num dos meus livros. Tinha um aluno obeso que não sabia como podia fazer participar nas aulas de educação física. Um dia decidi inventar um "crosse de precisão" em que cada grupo de alunos tinha que fazer o mesmo percurso duas vezes e procurar fazer

1- Uma corrida em que o objetivo não é chegar em primeiro lugar, mas sim realizar o percurso em um determinado tempo. (Nota das entrevistadoras). o tempo mais aproximado possível entre o primeiro e o segundo percurso. Este aluno, que não conseguia correr, mas caminhava com a precisão de um relógio suiço, fez a sua equipe ganhar, apesar de ser o último a chegar. Foi uma experiência espantosa para ele, para mim e para os colegas que, pela primeira vez, souberam que quem chega em último pode ganhar.

A minha experiência com a criação e a vivência de ambientes inclusivos foi muito enriquecida na universidade, dado que eu orientava de perto múltiplos estágios profissionais de professores, e aí tive a riquíssima experiência de acompanhar e avaliar o efeito de uma formação que não seja feita para ensinar o "aluno médio", e de como a diversidade de estratégias e de currículos na formação é fundamental para que os profissionais possam ser agentes de Inclusão. Escrevi mais tarde um artigo que retrata muito deste percurso intitulado Educação Inclusiva: como se reformam os reformadores?

A profissão de professor é muito solitária. Ou melhor, a sua solidão foi muito construída e alimentada. É como se a perspetiva individualista e meritocrática tão prevalente na escola tradicional não fosse exclusiva dos alunos, mas também dos professores. Esperase um professor onisciente e autossuficiente. De certo, esta nunca foi uma opção muito correta, mas o desenvolvimento da escola nas últimas décadas torna esta opção verdadeiramente absurda por três razões: a) o professor tem dificuldade em ensinar grupos cada vez mais heterogêneos, b) o professor deixou de ser a única fonte de informação, de conhecimento e de comunicação e c) a complexidade das suas tarefas (avaliação, flexibilização, organização da aprendizagem etc.). Por estes motivos, quebrar a solidão do professor não é só uma questão opcional: é uma questão vital, sem a qual ensinar e aprender se podem tornar empresas impossíveis. Um professor sozinho, sem apoio, sem a cooperação dos seus colegas difıcilmente poderá ser um professor capaz de 
responder capazmente aos desafios que a escola de agora lhe coloca.

0 senhor tem pesquisado e frequentemente discorre sobre os princípios que deveriam reger as escolas inclusivas. Poderia falar sobre isso?

Tenho alguma dificuldade com a palavra princípios, porque nos remete à ideia que há um caminho relativamente uniforme para encorajar e realizar práticas inclusivas. Vejo sempre todos os atos educativos como o encontro de múltiplas variáveis que podem ter presenças e valores muito diferentes. Sobre esta ausência de certezas absolutas de princípios relativamente estáveis lembro muitas vezes o título do livro de Perrenoud que é Educar: decidir na dúvida e agir na incerteza. Mas não quero fugir à resposta. Há valores que, mais cedo ou mais tarde, mais fortes ou mais discretos, tornam-se decisivos no florescer de práticas inclusivas. Ressaltaria três deles. Primeiro, destaco a determinação de educar todos os alunos. É um objetivo muito simples, mas ao mesmo tempo muito radical. A educação sempre conviveu com a possibilidade de perder alguns alunos. Estes “danos colaterais” eram sistematicamente justificados com as impossibilidades de adaptação a uma escola que, ela sim, era concebida como imutável. A mensagem da inclusão nesta matéria é muito clara: se não mudarmos os valores e as práticas da escola tradicional não conseguimos educar todos os alunos e logo ficamos longe de construir uma educação inclusiva.

Um segundo aspecto tem a ver com a reforma do trabalho de ensinar, do trabalho pedagógico. A inclusão pressupõe que se conheça e se leve em consideração o ponto de partida dos alunos. Costumo dizer que quem não sabe nada não pode aprender nada. Conhecendo o aluno, é preciso incentivar e acompanhar o seu caminho de aprendizagem, diversificando estratégias, diferenciando o currículo, adequando objetivos planejando experiências de inclusão e de entreajuda.
Por fim temos que considerar que a educação inclusiva é um processo muito mais lato do que a simples educação de alunos com condições de deficiência na escola regular. A educação inclusiva promove a participação e o sucesso de todos os alunos e, por isso, é difícil aceitar insucesso escolar numa escola que se queira aproximar dos valores inclusivos. Por vezes ouvimos dizer que "há alunos de inclusão", mas, na verdade, todos os alunos devem ser de inclusão. Tenho vindo a defender, especificamente no livro que acabo de publicar, Direitos Humanos e Inclusão (RODRIGUES, 2016), que a inclusão é um direito humano emergente e que, mais do que isso, é um direito que contribui decisivamente para "densificar" todos os outros direitos. Para isso precisamos que a inclusão seja um valor transversal da escola, seja um valor educativo de primeira linha, seja sobretudo um valor a que todos têm acesso. Já pensaram? Que direito temos nós, por exemplo, de privar alguns alunos do convívio e interação com outros alunos?

Criar ambientes inclusivos é um grande objetivo da melhoria da educação. Este ambiente inclusivo é um processo em que se identificam e procuram eliminar barreiras à aprendizagem de forma a conseguir a participação e o sucesso de todos os alunos. 0 ambiente inclusivo é um ambiente de aprendizagem em que é possível que todos os alunos aprendam uns com os outros, em que todos possam interagir e cooperar de uma forma cidadã e ética. Claro que pressupõe alterações muito substanciais na forma como a escola está organizada. Cito apenas três delas: modelos curriculares alargados e flexíveis, formas novas e criativas de interação e formas mais ativas de participação no trabalho pedagógico.

Outra escola é possível e/ou necessária para a efetivação dos princípios defendidos pelo senhor?

É possível outra escola? Claro que sim. Vejamos: no mesmo município, no mesmo estado, no mesmo país, escolas vizinhas têm práticas, 
resultados, valores e políticas diferentes. Mas se a legislação e a gestão central é a mesma como é que isso é possível? É possível porque a escola tem uma "autonomia relativa" e consegue por meio do trabalho dos professores, do trabalho das lideranças, da interação com a comunidade dar à escola características diferentes. Por isso, é tão importante que a escola conheça e exerça até ao seu limite a sua autonomia na gestão, no currículo e na criação de programas que mais se adequem aos seus alunos. A todos os seus alunos. Dou-lhe um exemplo: em Portugal uma bem conhecida escola do ensino médio decidiu acabar com as reprovações. A escola decidiu empreender programas de apoio aos alunos e de reconhecimento do nível que eles tinham alcançado que tornou as reprovações residuais. E aconteceu algo que parecia inesperado: os resultados da escola em nível nacional melhoraram. Este é só um pequeno exemplo para confirmar que é possível outra escola. Para isso é preciso um trabalho esclarecido, persistente e, sobretudo, coordenado, em que alunos, professores, famílias, comunidade sejam convocados para conseguir objetivos que compreendem e aceitam.

A segunda parte da questão é: é necessária outra escola? A resposta é afirmativa outra vez. Se não entendermos que a escola regular (um autor australiano, Roger Slee, afirmava que a escola regular é uma irregular school, porque exclui da aprendizagem e da educação muitos dos seus alunos) foi criada com base em valores que não são inclusivos, nunca iremos entender porque é necessário pugnar pela inclusão.

Temos que construir uma escola em que todos tenham lugar, em que todos se sintam bem vindos, uma escola que seja uma efetiva comunidade de aprendizagem em que todos - professores e alunos - aprendam e ensinem. Precisamos sim de outra escola e isso é largamente sentido por todas as pessoas que se relacionam com a educação. Gostava de chamar a atenção que quando digo outra escola não quero dizer a escola de antes. Pensar que os problemas de hoje podem ser resolvidos com soluções de ontem é um pouco ingênuo. Há pessoas que, em lugar de "utópicas" são "retrópicas", isto é pessoas que acham que a utopia está no regresso ao passado. Não são certamente estas as pessoas com que contamos para construir a escola inclusiva.

Em sua opinião existe uma condição humana mais desafiadora para o processo de escolarização?

A condição de deficiência tem uma função digamos que "profética" em relação à inclusão. Profética, porque anuncia a diversidade visível da nossa escola e que, por ser visível, torna-se impossível de ser ignorada. Olhando para uma pessoa com deficiência parece óbvio que é preciso e necessário que alguns aspectos do currículo tenham que ser adequados e adaptados para ela. Não é, pois de estranhar que, muitas vezes, a inclusão esteja centrada no processo social e escolar de pessoas com deficiência. Por vezes, ouvimos dizer que "esta escola não trabalha a inclusão porque não tem alunos com deficiência”. Nada mais errado: a inclusão é um valor transversal da escola e deve ser promovida para todos os alunos, tenham eles condições de deficiência ou não.

Dentro desta perspectiva inclusiva alargada, há, muitas vezes, "condições humanas" - como é evocado na pergunta - que são mais desafiadoras para a inclusão do que a deficiência. Por quê? Porque são condições que desafiam mais radicalmente os valores mais tradicionais da escola. E dou exemplos: crianças que têm graves perturbações do comportamento, que são disruptivas, agressivas com os colegas e com os professores, podem ser muito mais desafiadoras do que, por exemplo, um aluno com síndrome de Down. No meu país, muitas escolas que recebem alunos de etnia cigana enfrentam grandes dificuldades para conseguir compatibilizar a cultura cigana com a cultura escolar tal como a entendemos. Muitos professores dizem que preferiam ter alunos com deficiência a alunos de etnia cigana. 
A questão que me parece mais relevante nesta matéria é de que forma a escola está disposta, disponivel e desejosa de mudar as suas práticas mais transmissivas e normativas para entender e negociar com toda a grande diversidade que se encontra atualmente entre a população escolar. As condições mais desafiantes exigem escolas mais aptas e capazes para enfrentar estes desafios. A escola não pode perder este desafio, não pode perder nenhum aluno, porque esta perda é um caminho sem retorno. Cabe insistir na importância do fortalecimento da escola pública. Este fortalecimento passa por muitos fatores. Darei dois exemplos: os salários dos professores do ensino fundamental: a diferença salarial entre os professores universitários e os professores do ensino fundamental no Brasil pode beirar às dez vezes. Isto, na minha perspectiva, é uma injustiça e um obstáculo para o fortalecimento da escola. Por exemplo, no meu país esta diferença é bem inferior ao dobro. Um segundo aspecto é a necessidade de a escola ter tempo e estruturas para apoiar todos os alunos. E aí, penso que é fundamental que no Brasil se generalize a "escola em tempo integral". São dois exemplos simples e imediatos que me afiguram essenciais para fortalecer a escola.

Por ocasião do Fórum Mundial de Educação de 2015 (FME 2015), realizado na Coréia do Sul em Incheon, foi reafirmada a visão do movimento global Educação para Todos, iniciado em Jomtien, em 1990, e reiterado em Dakar, em 2000. Fruto desse evento, a Declaração de Incheon traz metas de Educação para Todos para os próximos catorze anos, de 2016 a 2030. Sumariamente, tal Declaração intenta, até 2030, "assegurar educação equitativa e inclusiva de qualidade e aprendizagem ao longo da vida para todos" (UNESCO, 2015, p. 1). Defende-se no documento uma educação inclusiva que e se adapte a cada estudante, que seja relevante para a sociedade e que respeite as diferentes culturas. Em sua opinião, como a inclusão e a equidade estão contempladas em tal documento?

A Declaração de Incheon é um daqueles documentos que devia ser obrigatório estudar em qualquer curso de pedagogia ou áreas correlacionadas. É um documento que aponta para princípios muito simples, mas também muito fundamentais. Por exemplo, lá se diz que "um objetivo só poderá ser considerado atingido se for atingido por todos os alunos". Já pensaram se isso fosse mesmo cumprido em todas as escolas? Originaria uma revolução copernicana em todo o trabalho pedagógico.

Quando se fala em equidade isso quer dizer "justiça social”, quer dizer que não podemos mais olhar a "igualdade de oportunidades" como se olhava há anos atrás, isto é, dar o mesmo a todos. Hoje sabemos que a equidade, a justiça social, pressupõe que o que se oferece seja compatível com as características e possibilidades de quem recebe. Por isso, aceitar que a equidade é um valor educativo renega a procura da homogeneidade, dos currículos de mão única, a utilização da reprovação como forma de exclusão primeira escolar e depois social.

Hoje assistimos a uma maior utilização do termo equidade, mas ele não substitui o termo inclusão (por muito desgastado e esvaído que esteja por tantas utilizações errôneas). A inclusão serve à equidade e certamente não pode existir uma sem a outra...

Que avaliação o senhor faz da possibilidade de efetivação dos princípios da inclusão e da equidade, dado o contexto vivido na Europa e na América Latina, de retomada de movimentos xenofóbicos e nacionalistas?

Não há dúvida de que vivemos tempos difíceis em nível mundial. Tempos em que nos parece que os valores dominantes cada vez mais se afastam da criação de comunidades e sociedades inclusivas. Boaventura Sousa Santos afırmava numa entrevista, em março deste ano (2016), que a educação se defronta com 
duas opções principais: a opção liberal, que considera haver uma incompatibilidade entre a liberdade e a igualdade e privilegia totalmente a liberdade, e a opção socialista democrática, que não só não vê compatibilidade entre a liberdade e a igualdade, mas ainda privilegia o conceito positivo de liberdade, como capacidade de cada um agir de modo a ter controle sobre a sua vida e atingir os seus objetivos.

Ora, esta opção liberal é muito prevalente no momento que atravessamos. Os sistemas educativos tendem a diminuir os seus serviços (a famosa teoria do "Estado mínimo") e esta diminuição, muitas vezes feita em nome da "liberdade", acaba por acentuar ainda mais as diferenças sociais. Precisamos de uma escola fortalecida, não mínima, mas máxima, uma escola que tenha recursos e confiança para encarar e lidar com os enormes desafios que se colocam à educação atual. A escola que diminui e que abandona os seus educandos aos serviços exteriores à escola está, na prática, a legitimar as diferenças que são agravadas pela falta de meios de ultrapassar os obstáculos.

$\mathrm{Na}$ verdade, não sou muito otimista sobre a inclusão e a equidade. Sei que temos um caminho árduo e longo pela frente. Por vezes, ouço opiniões a afırmar que a inclusão é inevitável e que, mais dia menos dia, inevitavelmente lá chegaremos. Eu prefiro dizer que a inclusão é uma pedra que custosamente levamos por uma encosta acima. Se pararmos por um momento para descansar, a pedra rola de novo para o sopé da montanha. E isto porque os valores efetivamente inclusivos, não estou a falar de conversa “da boca para fora”, não são os valores que são dominantes e que têm vencimento em grande parte dos sistemas educativos e em largas faixas dos sistemas educativos.

Não sou otimista, mas tenho esperança. Não a esperança de esperar (Chico Buarque de Holanda já escreveu há muito que "quem espera nunca alcança”), mas uma esperança de desbravar e de criar o que nunca vimos nem esperavamos ver. A minha esperança alicerçase no conhecimento que tenho das escolas e de como elas, os professores, as gestões e as comunidades são capazes de fazer maravilhas inesperadas quando se comprometem. Eu creio que a equidade e a inclusão são o futuro bom da humanidade, apesar de não saber se e quando eles vão triunfar. Eu certamente não verei esse triunfo, mas sei que é o lado certo para lutar, para cerrar fileiras num compromisso antes de mais de direitos humanos e de humanidade.

Gosto de pensar que somos como telhas: uma parte de nós é protegida pela telha de cima, isto é pelas referências que contribuíram para sermos o que somos, outra parte de nós é o nosso caminho mais autônomo e uma terceira parte de nós é a que protege e sustenta a telha seguinte. Gosto de pensar que é assim que temos de conceber a educação: num projeto a longo prazo a caminho da democracia, da participação, da justiça social e dos direitos humanos. 


\section{Bibliografia selecionada}

RODRIGUES, David. A inclusão nas escolas. Lisboa: Fundação Francisco Manuel dos Santos, 2014.

RODRIGUES, David. Educação e diferença: valores e práticas para uma educação inclusiva. Porto: Porto Editora, 2001.

RODRIGUES, David. Educação especial: deficiência motora: antologia de textos. Lisboa: ISEF, 1981.

RODRIGUES, David. Educação inclusiva: dos conceitos às práticas de formação. Lisboa: Instituto Piaget, 2011.

RODRIGUES, David. Equidade e educação inclusiva. Porto: Profedições. 2013.

RODRIGUES, David. Escola e integração na Europa: valores e práticas. Lisboa: SPCE, 1997.

RODRIGUES, David. Inclusão e educação: doze olhares sobre a educação inclusiva. São Paulo: Summus, 2006.

RODRIGUES, David. Percursos de educação inclusiva em Portugal: dez estudos de caso. Lisboa: FEEl, 2008.

RODRIGUES, David. Perspectivas sobre a inclusão: da educação à sociedade. Porto; Porto Editora, 2003.

RODRIGUES, David (Org.) Aprender juntos para aprender melhor. Lisboa: FEEI, 2007.

RODRIGUES, David (Org.). Investigação em educação inclusiva. v. 1. Lisboa: FEEI, 2006.

RODRIGUES, David (Org.). Investigação em educação inclusiva. v. 2. Lisboa: FEEI, 2007.

RODRIGUES, David (Org.). Os valores e as atividades corporais. São Paulo: Summus, 2008.

RODRIGUES, David; LIMA-RODRIGUES, Luzia. Formação de professores e inclusão: como se reformam os reformadores? Educar em Revista, Curitiba, n. 41, p. 41-60, 2011. Disponível em: <http://dx.doi.org/10.1590/S0104-40602011000300004>. Acesso em: 11 jan. 2017.

STOER, Stephen R.; MAGALHÃES, Antonio M.; RODRIGUES, David. Os lugares da exclusão social: um dispositivo de diferenciação pedagógica. São Paulo: Cortez, 2004. 